\title{
Influência do Método e Tempo de Armazenamento de Colmos de Capim-cameroon no seu Perfilhamento e Produção de Matéria Seca
}

\author{
Benedito Marques da Costa ${ }^{1}$, Dário Eloy Ribeiro², João Albany Costa ${ }^{3}$
}

\begin{abstract}
RESUMO - O objetivo deste estudo foi conhecer as influências dos métodos e tempos de armazenamentos de frações de colmos do capim-Cameroon (Pennisetum purpureum Schum. cv. Cameroon) no seu perfilhamento e produção de matéria seca, aos 70 dias após o plantio. O delineamento experimental foi em blocos casualizados, em esquema de parcelas divididas no tempo, com três repetições. Os métodos de armazenamento das frações de colmos foram: 1) amarradas em feixes; 2) amarradas em feixes e colocadas em sacos de polietileno com pequenos furos; 3) amarradas em feixes e colocadas em sacos de polietileno sem furos. Os tempos de armazenamento foram: $0,5,10,15,20,25$ e 30 dias. Verificou-se uma diferença entre os métodos de armazenamento das frações de colmos para número de perfilhos e para produção de matéria seca. O teor de umidade das frações de colmos foi afetado pelo método e pelo tempo de armazenamento. As frações de colmos de capim-cameroon podem ser armazenadas dentro de sacos de polietileno, perfurados ou não, durante 20 a 30 dias antes do plantio.
\end{abstract}

Palavras-chave: Pennisetum purpureum, armazenamento de colmos, número de perfilhos, produção de forragem

\section{Influence of Method and Storage Time of Stem Fractions of Cameroongrass on Tillering and Dry Matter Production}

\begin{abstract}
The objective of this study was to evaluate the influence of methods and storage times of stem fractions upon tillering and dry matter production of Cameroongrass (Pennisetumpurpureumcv. Cameroon) at 70 days after planting. Its propagation was carried out by planting culm fractions, each one containing four nodes. A split plot experiment design by time with 3 replications was used. Sorage methods of the stem fractions were: 1) tied bundles; 2) tied bundles and kept in plastic bags with small holes; 3) tied bundles and kept in plastic bags without holes. The storage times were 0, 5, 10, 15, 20, 25 and 30 days. A difference among storage methods of stem fractions for number of tillers and for dry matter production was observed. The water contents of stem fractions were affected by the storage methods as well as the storage times. The stem fractions of Cameroongrass could be stored in plastic bags with or without holes, for 20 or 30 days before planting.
\end{abstract}

Key Words: Pennisetum purpureum, storage of culms, number of tillers, forage production

\section{Introdução}

O capim-cameroon é uma cultivar do capimelefante (Pennisetum purpureum Schum.) que não apresenta floração (Mitidieri, 1983). Adapta-se bem tanto em solos arenosos quanto em argilosos, porém é bastante exigente em fertilidade de solo. Vegeta em regiões quentes e úmidas com precipitação anual de mais de $1000 \mathrm{~mm}$ e temperatura média de $24^{\circ} \mathrm{C}$ (Alcântara \& Bufarah, 1982). Essa cultivar tem mostrado bom comportamento nas condições edafoclimáticas do município de Cruz das Almas BA, revelando-se uma gramínea de corte promissora para alimentação de ruminantes.
A produção de matéria seca de uma forrageira é a sua produção de forragem livre de água. Paz \& Faria (1978), avaliando quatro cultivares de capimelefante (Cameron, Vruckwona, Taiwan A-148 e Taiwan A-241), em Piracicaba, SP, obtiveram maiores rendimentos de matéria seca para a cultivar Cameroon, que produziu 4660 e $6470 \mathrm{~kg} / \mathrm{ha}$, respectivamente, aos 63 e 78 dias de crescimento, no auge e final da estação chuvosa. No Rio Grande do Sul, Poli et al. (1991), avaliando as cultivares Cameroon, Mineiro, Taiwan A-146 e Taiwan A-241, constataram que o rendimento total de matéria seca das cultivares Taiwan A-241 e Cameroon foi superior $(\mathrm{P}<0,05)$ ao das demais. Em Itajuí do Colônia, na

1 Professor Titular, Departamento de Zootecnia, Escola de Agronomia/UFBA. E.mail: bmarques@ufba.br

2 Professor Substituto, Departamento de Química Agrícola e Solos, Escola de Agronomia/UFBA.

3 Professor Adjunto, Departamento de Engenharia Agrícola, Escola de Agronomia/UFBA. 
Bahia, Santana et al. (1994), avaliando as cultivares Cameroon, Mineiro e Napier de Goiás, concluíram que a cultivar Cameroon apresentou maior produção de matéria seca que a Mineiro e produção semelhante a do Napier de Goiás. Carvalho (1996), avaliando quatro acessos de capim-elefante (Roxo de Botucatu, Cameroon, Guaçu e Uruckwanu), concluiu que o acesso Uruckwanu apresentou as melhores produções de matéria seca, com boa produção estacional. Queiroz Filho et al. (1998), avaliando quatro cultivares de capim-elefante (Roxo, Cameroon, Gramafante e Mineirão), não encontraram diferença significativa entre as cultivares quanto à produção de matéria seca da parte aérea. Contudo, novos clones de capimelefante, avaliados por Botrel et al. (2000), apresentaram maior produção de matéria seca que as cultivares tradicionais Cameroon e Taiwan A-146, durante os períodos seco e chuvoso.

O plantio de variedades e cultivares de capimelefante geralmente é feito por pedaços de colmo porque suas sementes apresentam baixa porcentagem de germinação. Ademais, Xavier et al. (1993), ao estudarem o poder germinativo de sementes de 60 acessos de capim-elefante, verificaram que apenas seis acessos não floresceram, sendo eles Cubano Pinda, Cameroon, Vruckwona, Bag 50, IAC - Campinas e Cana d'África. Esse fato faz com que haja a necessidade de grandes quantidades de colmos para plantio de uma área de capineira. Mozzer \& Andrade (1985) informam que, no espaçamento próximo de $0,80 \mathrm{~m}$ entre sulcos, o gasto é de 3 a 4 t/ha de colmos. Segundo esses autores, de um hectare tiram-se colmos para plantar, em média, 10 hectares de capineira.

Os sulcos devem ser feitos a uma profundidade de 10 a $15 \mathrm{~cm}$. Os pedaços de colmos são, então, dispostos dentro do sulco de modo contínuo e, em seguida, cobertos com pequena camada de terra (Mozzer \& Andrade, 1985).

O pedaço de colmo para dar boa brotação, na maioria das gemas, deve ser oriundo de uma planta com, no mínimo, 90 a 120 dias de idade, sem ainda ter liberado os perfilhos axilares. Assim, os pedaços de colmos destinados ao plantio deverão apresentar gemas axilares bem desenvolvidas, maduras, localizadas nos seus nós. Portanto, o conhecimento do tempo em que as frações de colmos podem ser armazenadas e, posteriormente, permanecerem viá veis é de primordial importância para o êxito no plantio e na formação de capineiras.

Os objetivos deste estudo foram conhecer os efeitos de três métodos e sete tempos de armazenamento de frações de colmo de capimcameroon sobre o número de perfilhos e a produção de matéria seca.

\section{Material e Métodos}

O estudo foi conduzido na Escola de Agronomia da UFBA, no município de Cruz das Almas - BA, durante o período de julho a novembro de 1990. O município está situado na região fisiográfica do Recôncavo Baiano, apresentando as coordenadas geográficas de $12^{\circ} 40^{\prime} 19^{\prime}$ de latitude sul e $39^{\circ} 06^{\prime} 23^{\prime \prime}$ de longitude oeste de Greenwich e altitude média de $220 \mathrm{~m}$.

O clima, segundo a classificação de Thornthwaite e Mather, é do tipo subúmido, com pluviosidade média anual de $1170 \mathrm{~mm}$, com variações entre 900 e $1300 \mathrm{~mm}$, sendo os meses de março a agosto os mais chuvosos e setembro a fevereiro os mais secos. A temperatura média anual é de $24,1^{\circ} \mathrm{C}$ e o balanço hídrico apresenta uma evapotranspiração potencial de $1267 \mathrm{~mm}$ anuais, havendo excedente hídrico apenas durante os meses de junho, julho e agosto. O solo é classificado como Latossolo Amarelo álico coeso, de textura argilosa e relevo plano (Ribeiro et al., 1995). A análise química da amostra do solo revelou os seguintes valores: $\mathrm{pH}$ em água $=5,6 ; \mathrm{Al}^{+3}=0,1 \mathrm{meg} / 100 \mathrm{~g} ; \mathrm{Ca}^{+2}+\mathrm{Mg}^{+2}=$ $1,8 \mathrm{meg} / 100 \mathrm{~g} ; \mathrm{P}=15 \mathrm{ppm}$; e $\mathrm{K}=48 \mathrm{ppm}$.

Os colmos usados foram oriundos de plantas com, aproximadamente, 90 dias de idade. Após um corte a $10 \mathrm{~cm}$ acima do solo, cerca de $30 \mathrm{~cm}$ de suas pontas foram eliminadas. Os colmos dos diferentes tratamentos foram cortados de 5 em 5 dias, sendo cada um cortado em pedaços contendo quatro gemas, amarrados em feixes de 33 unidades e guardados à sombra, em uma dependência do Departamento de Zootecnia da Escola de Agronomia da UFBA, segundo o método e tempo de armazenamento.

Os métodos de armazenagem dos pedaços de colmos foram: 1) amarrados em feixes; 2) amarrados em feixes e acondicionados em sacos de polietileno com furos; 3) amarrados em feixes e acondicionados em sacos de polietileno sem furos. Os feixes de frações de colmos foram submetidos aos seguintes tempos de armazenamento, antes do plantio: 0 , 5, 10, 15, 20, 25 e 30 dias. Os colmos das plantas foram cortados a cada 5 dias, a partir do tempo de armazenamento de 30 dias até o tempo zero, permitindo que todos os pedaços de colmos fossem plantados no mesmo dia, após o vencimento dos períodos de 
armazenamento. As variáveis estudadas foram: a) teor de umidade (\%) das frações dos colmos; b) produção de matéria seca $(\mathrm{kg} / \mathrm{ha})$ e número de perfilhos por parcela útil $\left(2,8 \mathrm{~m}^{2}\right)$, aos 70 dias após o plantio.

Realizou-se uma calagem em cobertura, seguida de aração, gradagem e sulcamento das parcelas, na profundidade de $15 \mathrm{~cm}$, no espaçamento de $0,70 \mathrm{~m}$. Dentro dos sulcos, realizou-se uma adubação NPK, nas quantidades de $90 \mathrm{~kg} / \mathrm{ha}$ de $\mathrm{N}$, sob a forma de sulfato de amônio, $60 \mathrm{~kg} / \mathrm{ha}$ de $\mathrm{P}_{2} \mathrm{O}_{5}$, sob a forma de superfosfato simples, $80 \mathrm{~kg} / \mathrm{ha}$ de $\mathrm{K}_{2} \mathrm{O}$, sob a forma de cloreto de potássio, conforme os resultados de análise de solo. A quantidade do adubo nitrogenado (sulfato de amônio) foi fracionada em duas aplicações; a metade por ocasião do plantio e a outra metade 30 dias após. Os colmos foram plantados continuamente dentro dos sulcos, colocando-se sete pedaços com quatro gemas por fileira de $2,40 \mathrm{~m}$, perfazendo um total de 28 pedaços por parcela.

No tempo 0 (zero) e após o término de cada tempo de armazenamento das frações de colmo, tomou-se de cada feixe uma amostra de cinco pedaços para as determinações de umidade. Os teores de umidade dos pedaços de colmo e matéria seca dos perfilhos foram determinados em estufa de circulação de ar a $65^{\circ} \mathrm{C}$ (pré-secagem), durante 72 horas, e a secagem definitiva, em estufa a $105^{\circ} \mathrm{C}$, durante três horas, segundo Silva (1990).

Cada parcela tinha dimensões de 2,4 $\mathrm{m}$ x 2,80 m, sendo abertos quatro sulcos espaçados de $0,70 \mathrm{~m}$. A área da parcela útil era de $2,80 \mathrm{~m}^{2}(2,00 \mathrm{~m} \times 1,40 \mathrm{~m})$ correspondente às duas fileiras de 2 metros de comprimento, desprezando-se duas fileiras laterais e $0,20 \mathrm{~m}$ nas cabeceiras da parcela. A colheita para produção de matéria seca e a contagem do número de perfilhos foram realizadas, na área útil, 70 dias após a data do plantio.

O delineamento experimental foi em blocos casualizados, com três repetições, em esquema de parcelas divididas no tempo. Os tratamentos (três métodos e sete tempos de armazenamento de pedaços de colmo) foram analisados de acordo com o modelo estatístico:

$$
\begin{gathered}
\mathrm{Y}_{\mathrm{ijk}}=\mu+\mathrm{M}_{\mathrm{i}}+\mathrm{B}_{\mathrm{j}}+(\mathrm{MB})_{\mathrm{ij}}+\mathrm{T}_{\mathrm{k}}+(\mathrm{MT})_{\mathrm{ik}}+ \\
(\mathrm{BT})_{\mathrm{jk}}+\mathrm{E}_{\mathrm{ijk}}
\end{gathered}
$$

em que $\mathrm{Y}_{\mathrm{ijk}}=$ observação relativa ao método ${ }_{\mathrm{i}}$ no tempo de armazenamento ${ }_{\mathrm{k}}$ no bloco ${ }_{\mathrm{j}} ; \mu=$ média geral; $\mathrm{M}_{\mathrm{i}}=$ efeito do método ${ }_{\mathrm{i}}(\mathrm{i}=1,2,3) ; \mathrm{B}_{\mathrm{j}}=$ efeito do bloco $_{\mathrm{j}}(\mathrm{j}=1,2,3) ;(\mathrm{MB})_{\mathrm{ij}}=$ efeito da interação do método $_{\mathrm{i}}$ com o bloco ${ }_{\mathrm{j}} ; \mathrm{T}_{\mathrm{k}}=$ efeito do tempo de armazenamento $_{\mathrm{k}(\mathrm{k}=1,2,3,4,5,6,7)}$; (MT) $)_{\mathrm{ik}}=$ efeito da interação do método ${ }_{\mathrm{i}}$ com o tempo de armazenamento ${ }_{\mathrm{k}}$;

Tabela 1 - Graus de liberdade, quadrados médios e coeficientes de variação para produção matéria seca, número de perfilhos e teor de umidade de pedaços de colmo de capim-cameroon, submetidos a três métodos e sete tempos de armazenamento

Table 1 - Degrees of freedom, mean squares and coefficient of variation for dry matter production, number of tillers and humidity content of cameroon grass culm fractions,

\begin{tabular}{|c|c|c|c|c|}
\hline $\begin{array}{l}\text { Fonte de variação } \\
\text { Source of variation }\end{array}$ & $\begin{array}{l}\mathrm{gl} \\
d f\end{array}$ & $\begin{array}{l}\text { Matéria seca } \\
\text { Dry matter }\end{array}$ & $\begin{array}{c}\text { Número } \\
\text { de perfilhos } \\
\text { Tillers number }\end{array}$ & $\begin{array}{l}\text { Teor de umidade } \\
\text { Humidity content }\end{array}$ \\
\hline Blocos - Bl & 2 & 1,18 & $5,13 *$ & 14,62 \\
\hline $\begin{array}{l}\text { Blocks } \\
\text { Método - M } \\
\text { Method }\end{array}$ & 2 & $8,01 *$ & $15,00 * *$ & $358,24 * *$ \\
\hline $\begin{array}{l}\text { Resíduo (a) } \\
\text { Error }(a)\end{array}$ & 4 & 0,49 & 0,49 & 11,15 \\
\hline Tempo-T & 6 & 0,25 & 0,65 & $114,10 * *$ \\
\hline $\begin{array}{l}\text { Time - T } \\
\text { M x T } \\
\text { Bl } \times T \\
\text { Resíduo (b) }\end{array}$ & $\begin{array}{l}12 \\
12 \\
22\end{array}$ & $\begin{array}{l}0,46 \\
0,25 \\
0,54\end{array}$ & $\begin{array}{l}1,08 \\
0,58 \\
1,36\end{array}$ & $\begin{array}{l}58,31 * * \\
26,52 * \\
10,78\end{array}$ \\
\hline $\begin{array}{l}\text { Error (b) } \\
\text { CV (\%) }\end{array}$ & & 10,38 & 20,92 & 4,98 \\
\hline
\end{tabular}
under three methods and seven storage times

* Significativo $(\mathrm{P}<0,05)$.

* Significant $(P<.05)$.

** Significativo $(P<0,01)$.

** Significant $(P<.01)$. 


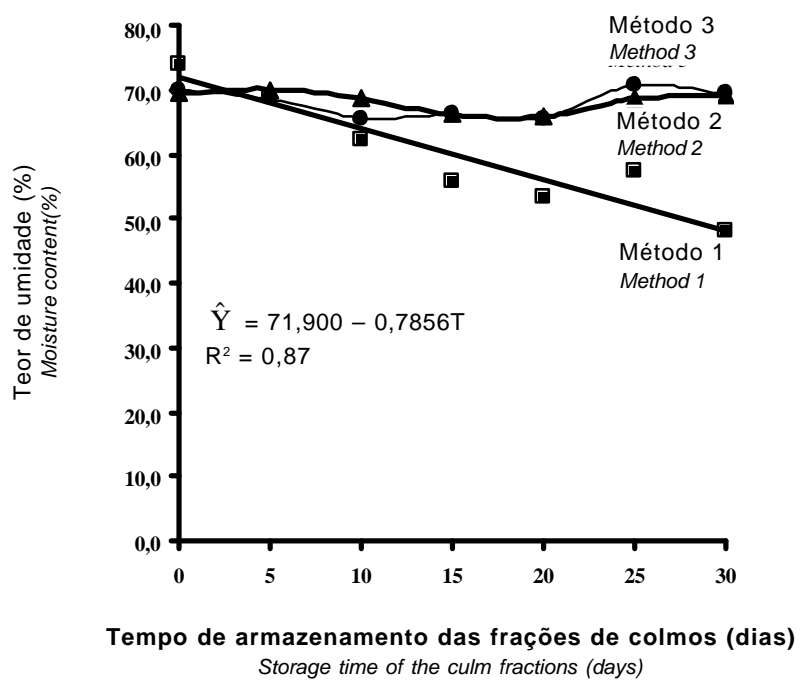

Figura 1 - Teor de umidade das frações de colmos de capim-Cameroon.

Figure 1 - Moisture content of the culm fractions of Cameroongrass.

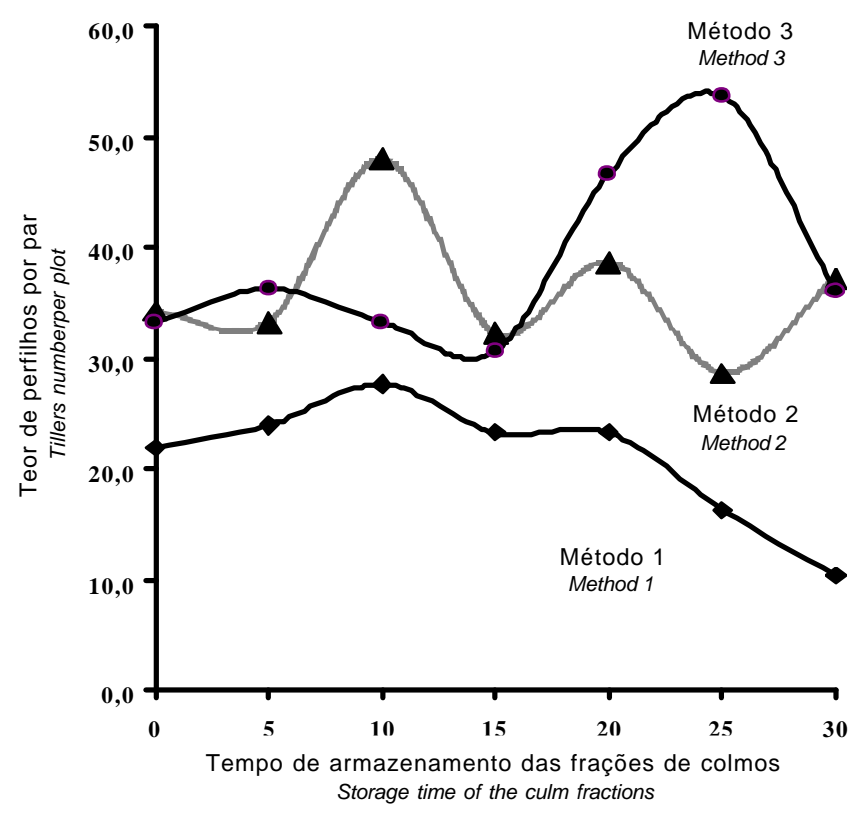

Figura 2 - Número de perfilhos por parcela de capimCameroon em função do método e do tempo de armazenamento das frações de colmos.

Figure 2 - Tillers number of cameroongrass per plot according to the method and storage time of the culm fractions.

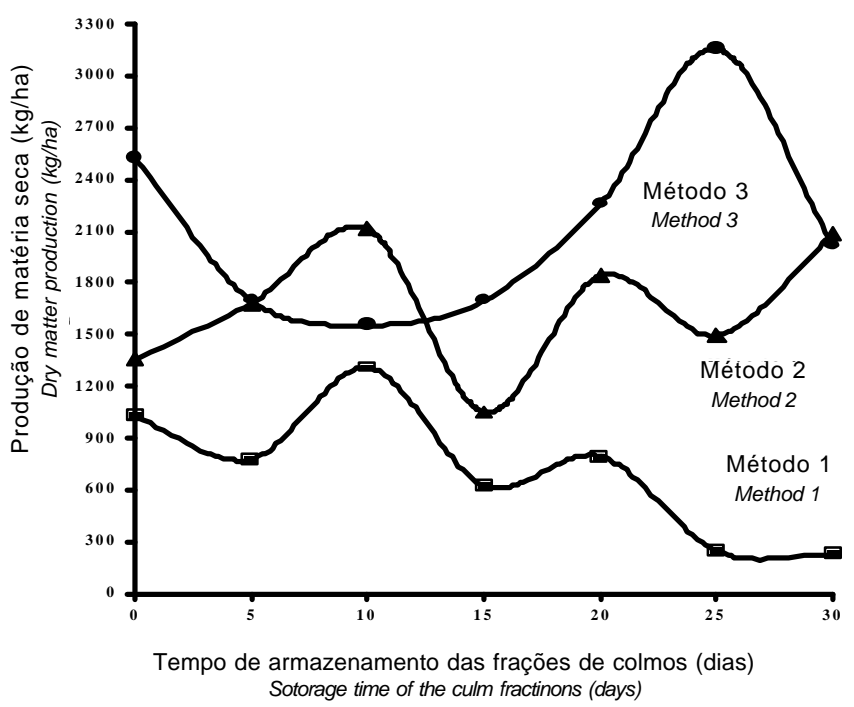

Figura 3 - Produção de matéria seca de capimCameroon, em função do método e do tempo de armazenamento das frações de colmos.

Figure 3 - Dry matter production of Cameroongrass, according to the method and storage time of the culm fractions.

$(\mathrm{BT})_{\mathrm{jk}}=$ efeito da interação do bloco $_{\mathrm{j}}$ com o tempo de armazenamento $_{\mathrm{k}} ; \mathrm{E}_{\mathrm{ijk}}=$ erro experimental.

Para a análise estatística, os dados foram submetidos às análises de variância e regressão, utilizando-se o programa SAEG (Sistema de Análises Estatísticas e Genéticas), conforme descrito por Euclydes (1982).

\section{Resultados e Discussão}

Verificou-se diferença significativa entre os métodos de armazenamento das frações de colmo para produção de matéria seca $(\mathrm{P}<0,05)$ e número de perfilhos $(\mathrm{P}<0,01)$ (Tabela 1). O teor de umidade dos pedaços de colmo foi afetado tanto pelo método como pelo tempo de armazenamento em que foram submetidos $(\mathrm{P}<0,01)$. A decomposição do efeito da interação M x $\mathrm{T}$ (método $\mathrm{x}$ tempo de armazenamento das frações de colmos) revelou uma variação significativa da umidade, em função do tempo de armazenamento das frações de colmo, segundo a equação $\hat{Y}=71,900-0,7856 \mathrm{~T} ; \mathrm{R}^{2}=0,87$ para o método 1 (pedaços de colmos amarrados em feixes), enquanto os outros métodos apresentaram variações casuais da umidade ao longo do tempo (Figura 1). 
Observou-se, portanto, que cada cinco dias de armazenamento determinou, em média, redução de $3,9 \%$ no teor de umidade do material armazenado segundo este método.

No método 1, os pedaços de colmo amarrados em feixes apresentaram redução no teor de umidade durante o tempo de armazenamento. Essa redução pode ter influenciado o número de perfilhos e a produção de matéria seca 70 dias após o plantio (Figuras 2 e 3 ).

Nos métodos 2 (pedaços de colmos armazenados dentro de sacos de polietileno com furos) e 3 (pedaços de colmos armazenados dentro de sacos de polietileno sem furos), as frações de colmos apresentaram tendência de manutenção dos teores de umidade, embora mostrassem alguma variação ascendente, provavelmente em razão de o saco de polietileno ter mantido melhor condição de umidade e, também, da qualidade das frações de colmos.

As produções de matéria seca de cultivares de capim-elefante podem ser afetadas pelas diferentes localizações das frações do colmo usadas no plantio. No presente trabalho, da cv. Cameroon foram eliminadas cerca de $20 \mathrm{~cm}$ da porção apical de cada colmo, sendo o restante dividido em frações (pedaços), que foram usadas no armazenamento e plantio. Contudo, em trabalho relatado por Viana et al. (1990), com as cultivares Roxo, Cameroon e Vruckwona, as maiores produções de matéria seca ocorreram quando foi usada a fração apical $(29,1 ; 29,3$ e 30,6 t/ha) e as menores, a fração intermediária (24,2; 21,1 e 22,8 t/ha), respectivamente.

Não se observou efeito do tempo de armazenamento sobre a produção de matéria seca $(\mathrm{kg} / \mathrm{ha})$ e sobre o número de perfilhos/parcela $(\mathrm{P}>0,05)$. Esses resultados diferem dos de Alcântara et al. (1980), que observaram decréscimo quase linear na porcentagem de brotamento das gemas de colmos de capim-elefante, à medida que se aumentou o tempo de armazenamento para até cinco dias. A partir daí, até 15 dias de armazenamento, a percentagem de gemas brotadas se manteve mais ou menos constante.

\section{Conclusões}

Frações de colmos de capim-elefante (Pennisetum purpureum Schum.) cv. Cameroon podem ser armazenadas dentro de sacos de polietileno, perfurados ou não, durante 20 a 30 dias antes do plantio.

\section{Literatura Citada}

ALCÂNTARA, P.B.; ABRAMIDES, P.L.G.; REIS, A.A. et al. Efeito do tempo de armazenamento na viabilidade de gemas de capim elefante (Pennisetum purpureum Schum.)Boletim de Indústria Animal, v.37, n.1, p.103-108, 1980.

ALCÂNTARA, P.B.; BUFARAH, G. Plantas forrageiras: gramíneas e leguminosas. São Paulo: Nobel, 1982. 150p.

BOTREL, M.A.; PEREIRA, A.V.; FREITAS, V.P. et al. Potencial forrageiro de novos clones de capim-elefante. Revista Brasileira de Zootecnia, v.29, n.2, p.334-340, 2000.

CARVALHO, D.D. Competição entre quatro acessos de capimelefante Pennisetum purpureum Schum) In: REUNIÃO ANUAL DA SOCIEDADE BRASILEIRA DE ZOOTECNIA, 33., 1996, Fortaleza. Anais... Fortaleza: Sociedade Brasileira de Zootecnia, 1996. p.1-3.

EUCLIDES, R.F. SAEG - Sistema de análises estatísticas e genéticas. Viçosa: UFV, Central de Processamento de Dados, 1982. $68 \mathrm{p}$.

MOZZER, O.L.; ANDRADE, I.F. Formação e manejo de capineira. Informe Agropecuário, v.11, n.132, p.78-84, 1985.

MITIDIERI, J. Manual de gramíneas e leguminosas para pastos tropicais. São Paulo: Nobel, 1983. 198p.

PAZ, L.G.; FARIA, V.P. Produção de matéria seca e valor nutritivo de variedades de capim-elefante (Pennisetum purpureum, Schum) fertilizadas com Wuscal e Wuscal LVC através de adubação foliar.Revista Brasileira de Zootecnia, v.7, n.1, p.94-114, 1978.

POLI, C.H.E.C.; PEREIRA, J.M.; ARRUDA. N.G. et al. Avaliação de cultivares de capim-elefante, produção de matéria seca, relação folha/colmo e capacidade de afilhamento. In: REUNIÃO ANUAL DA SOCIEDADE BRASILEIRA DE ZOOTECNIA, 28., 1991, João Pessoa. Anais... João Pessoa: Sociedade Brasileira de Zootecnia, 1991. p.9.

QUEIROZ FILHO, J.L.; SILVA, D.S.; NASCIMENTO, I.S. et al. Produção de matéria seca e qualidade de cultivares de capim-elefante (Pennisetum purpureum, Schum). Revista Brasileira de Zootecnia, v.27, n.2, p.262-266, 1998.

RIBEIRO, L.P.; SANTOS, D.M.B.; LIMA NETO, I.A. et al. Levantamento detalhado dos solos, capacidade de uso e classificação de terras para irrigação da Estação de Plasticultura da Universidade Federal da Bahia/Politeno em Cruz das Almas (BA). Revista Brasileira de Ciência do solo, v.19, n.1, p.105-113, 1995

SANTANA, J.R.; PEREIRA, J.M.; RUIZI, M.A.M. Avaliação de cultivares de capim-elefante (Pennisetum purpureum Schum.) no sudoeste da Bahia. II-Agrossistema de Itapetinga. Revista Brasileira de Zootecnia, v.23, n.4, p.507-517, 1994.

SILVA, D.J. Análise de alimentos: métodos químicos e biológicos. Viçosa, MG: Universidade Federal de Viçosa, 1990. 165p.

VIANA, O.J.; CARNEIRO, M.S.S.; CABRAL, G.H. Avaliação de diferentes frações do colmo no plantio de cultivares de capim-elefante (Pennisetum purpureum Schum) In: REUNIÃO ANUAL DA SOCIEDADE BRASILEIRA DE ZOOTECNIA, 27., 1990, Campinas. Anais... Piracicaba: Fundação de Estudos Agrários Luiz de Queiroz, 1990. p.289.

XAVIER, D.F.; DAHER, R.F.; BOTREL, M.A. et al. Poder germinativo de sementes de capim-elefante. Revista Brasileira de Zootecnia, v.22, n.4, p.565-571, 1993.

Recebido em: 04/10/02 Aceito em: 28/07/03 